\title{
Pengaruh Revitalisasi Sungai Terhadap KinerJa Sistem Drainase Kali Pepe Hilir Kota Surakarta
}

\author{
Reza Eka Putri Damayanti \\ PROGRAM STUdi PERENCANAAN WILAYAH DAN KotA \\ FAKULTAS TEKNIK \\ UnIVERsitas SEBElas MARET, SURAKARTA \\ KUSWANTO NURHADI \\ PROGRAM STUDi PERENCANAAN WILAYAH DAN KOTA \\ FAKULTAS TEKNIK \\ UNIVERSITAS SEBElas MARET, SURAKARTA \\ ISTI ANDINI \\ Program Studi PERENCANAAN Wilayah DAN Kota \\ FAKULTAS TEKNIK \\ Universitas SEbElas Maret, SuRAKarta
}

\begin{abstract}
Flood in Surakarta mostly due to overflowing rivers that flow through the region of Surakarta. The river is part of the urban drainage system. Department of Public Works (DPU) as the local government agency is responsible for the drainage management in Surakarta. One of form of implementation of the river management as part of drainage system is river revitalization program of Pepe River downstream which performed by the DPU. Despite Pepe River downstream revitalization program has been implemented in a variety of activities, the event of flooding due to overflowing Pepe River downstream still occur. Where as the flood is one of the performance indicators of urban drainage system. Thus, from that background it can be defined in research formulation problems, that is how the influence of the river revitalization performed by the DPU Surakarta against Pepe River downstream performance as part of urban drainage system in Surakarta.

This research uses quantitative descriptive analysis supported by several analytical techniques including descriptive narrative analysis to identify the characteristics of the revitalization of Pepe River downstream and paired simple t-test analysis to identify the changes of drainage system performance. Next, the relations from the results of both analysis will be identified using explanatory descriptive analysis. Based on the analysis results, it shows that the characteristics of the revitalization of Pepe River downstream is categorized in moderate intensity, because it only includes physical and social activities. Although there are improved changes in the drainage system performance. On the river section I, there are less significant changes with the number of the biggest changes ison the indicator of gabions, that is 11 . On the river section II, the drainage system performance changes are significant with the number of the biggest changes is on the indicator of sedimentation, that is 38. In river section III, there are less significant changes with the number of the biggest change is on the indicator of garbage accumulation, with a score of 21.Therefore, it can be argued that the river revitalization program performed by the DPU Surakarta affects the Pepe River downstream performance as the primary drainage channel in the drainage system in Surakarta. The influence can be seen from the reversion of river functions as a drainage channel which is marked by changes in Pepe River downstream drainage system performance from before the river revitalization performed and after the revitalization performed, which is improved.
\end{abstract}

Keywords: river revitalization, catchment area, drainage system performence

\section{PENDAHULUAN}

Banjir atau genangan di suatu kawasan permukiman masih banyak

terjadi di berbagai kota di Indonesia. Banjir atau genangan di suatu kawasan 
terjadi apabila sistem drainase yang berfungsi untuk menampung genangan itu tidak mampu menampung debit yang mengalir. Pada kawasan perkotaan, drainase perkotaan itu sendiri berfungsi untuk mengeringkan bagian-bagian wilayahadministrasi kota dan daerah urban darigenangan air, baik dari hujan lokal maupun luapan sungai yang melintas di dalam kota (SK Menteri Pekerjaan Umum 233 tahun 1987). Banjir di kota Surakarta sebagian besar terjadi karena luapan sungai yang mengaliri wilayah Surakarta. Banjir akibat luapan Bengawan Solo terjadi di Kota Surakarta dikarenakan letak Kota Surakarta yang merupakan bagian wilayah hulu Bengawan Solo dan memiliki elevasi muka tanah yang relatif rendah (Kepmen PU No 266 Tahun 2010 tentang Pola Pengelolaan Sumber Daya Air Wilayah Sungai Bengawan Solo). Sehingga ketika debit Bengawan Solo naik maka wilayah Surakarta akan terjadi genangan bahkan banjir. Pada kasus banjir yang terjadi pada anak sungai Bengawan Solo, pada umumnya karena penurunan fungsi sungai sebagai saluran drainase primer kota yang dilihat dari buruknya kondisi badan sungai dan sempadan sungai sehingga meningkatkan potensi terjadi banjir akibat luapan sungai tersebut Maryono (2003) dalam Atmaka (2004).

Pengelolaan sistem drainase termasuk di dalamnya sungai menjadi bagian dari pengendali banjir (flood control) yang mempengaruhi persebaran titik genangan dan banjir yang ada di Kota Surakarta.. Pengelolaan sistem drainase yang ada di Kota Surakarta merupakan tugas dari Dinas Pekerjaan Umum yang memiliki fungsi di antaranya adalah pembangunan, operasi dan pemeliharaan drainase. Revitalisasi sungai merupakan proyek pemerintah dalam pengelolaan sungai sebagai bagian dari sistem drainase yang diharapkan dapat mengurangi kejadian banjir yang terjadi di Kota Surakarta yang dilakukan oleh DPU. Revitalisasi sungai sendiri merupakan suatu usaha untuk mengembalikan fungsi-fungsi sungai yang meliputi fungsi sebagai saluran eko - drainase, fungsi saluran irigasi, dan fungsi ekologi agar berfungsi sebagaimana mestinya. Revitalisasi sungai merupakan suatu konsep untuk mengoreksi dari konsep pembangunan sungai sebelumnya (Maryono, 2007)

Kali Pepe Hilir masuk menjadi prioritas pengelolaan sungai oleh Pemerintah Kota Surakarta berdasarkan pedoman penataan Kali Anyar dan Kali Pepe yang dirumuskan oleh BBWS Bengawan Solo.Selain itu, pada Kali Pepe Hilir telah banyak dilakukan kegiatankegiatan sebagai bentuk dari implementasi revitalisasi sungai yang dilakukan oleh DPU seperti pengerukan sedimen dan sampah, pembuatan dan penambahan talud/ dinding saluran serta kegiatan bersih-bersih sungai. Namun, sungai ini masih sering meluap dan mengakibatkan genangan di wilayah di sekitar kali Pepe Hilir. Disisi lain, sungai yang memiliki fungsi sebagai saluran drainase dikatakan baik jika kinerja sistem drainase tersebut juga baik. Kinerja sistem jaringan drainase adalah bagaimana hasil sistem drainase yang sudah dibangun dapat mengatasi permasalahan genangan(Suryanti, Norken dan Sila, 2013).

\section{METODE PENELITIAN}

Ruang lingkup wilayah penelitian yaitu kelurahan-kelurahan yang dilewati oleh Kali Pepe Hilir. Dan pendalaman data untuk program revitalisasi hanya berdasarkan bentuk kegiatan, lokasi dan waktu, sedangkan kinerja drainase hanya berdasarkan ada tidaknya indikator tersebut di wilayah penelitian.

Untuk data terkait dengan program revitalisasi dilihat secara time series yaitu program pengelolaan sungai oleh DPU mulai tahun 2008 sampai dengan 2013. Karena pada tahun 2007 DPU belum fokus terhadap pengelolaan sungai yang ada di Kota Surakarta. Data terkait kinerja drainase dilihat pada tahun sebelum dan sesudah dilakukannya revitalisasi sungai, yaitu pada tahun 2007 dan 2014. Sehingga kinerja drainase dapat dinilai perubahannya dan diketahui apakah perubahan tersebut dipengaruhi oleh 
revitalisasi sungai yang telah dilakukan selama ini oleh DPU.

Penelitian ini merupakan penelitian deskriptif dengan menggunakan pendekatan deduktif, yaitu penelitian yang dilakukan dengan berdasarkan pada teori, kasus dan studi literatur untuk menguji pertanyaan penelitian yang diturunkan dari teori. Teori terlebih dahulu dijelaskan secara eksplisit untuk kemudian dapat dilanjutkan untuk menguji pertanyaan penelitian.

Teknik analisis yang digunakan dalam penelitian in secara garis besar menggunakan analisis secara deskriptif kuantitatif dan analisis perbandingan yaitu Paired Sample T-Test. Penelitian ini merupakan penelitian studi kasus dengan metode studi dokumentasi untuk mebcari data revitalisasi sungai dan observasi langsung ke lapangan serta kuisioner untuk mencari data terkait kinerja sistem drainase pada Kali Pepe Hilir. Analisis yang digunakan terdiri dari empat tahapan yaitu: (1) Analisis Pembagian Wilayah Sungai, Analisis ini hanya sebagai dasar dari analisisnya berikutnya. Analisis ini akan menghasilkan bagian wilayah sungai pada Kali Pepe Hilir, dimana setiap bagian sungai memiliki karakteristik yang berbeda, dilakukan dengan teknik analisis overlay; (2) Analisis Karakteristik Revitalisasi Kali Pepe Hilir, Analisis ini dilakukan untuk mengidentifikasi karakteristik revitalisasi sungai yang didapat dari data sekunder tentang lokasi, waktu dan bentuk kegiatan, yang telah dilakukan oleh DPU Kota Surakarta di Kali Pepe Hilir dilakukan dengan teknik analisis deskriptif narasi; (3) Analisis Perubahan Kinerja Sistem Drainase Kali Pepe Hilir, Analisis ini dilakukan untuk mengetahui ada tidaknya perubahan dan besarnya perubahan pada tiap indikator kinerja sistem drainase pada Kali Pepe Hilir antara sebelum dan sesudah dilakukannya revitalisasi sungai, dilakukan dengan teknik analisis paired sample t-test dan skoring; (4) Analisis Pengaruh Revitalisasi Sungai Terhadap Kinerja Sistem Drainase Kali Pepe Hilir, Analisis ini digunakan untuk melihat bagaimana pengaruh revitalisasi terhadap kinerja drainase dengan mengidentifikasi hubungan yang terjadi antara intensitas revitalisasi yang telah dilakukan oleh DPU terhadap perubahan pada masing-masing indikator kinerja sistem drainase yang dilihat pada tiap bagian sungai, dilakukan dengan teknik analisis deskriptif ekplanasi.

\section{HASIL DAN PEIMBAHASAN}

\section{Pembagian Wilayah Sungai}

Pembagian wilayah sungai merupakan bagian dari pengelolaan sungai dengan cara mengelompokkan sungai berdasarkan persamaan karakteristik yang dimiliki sungai tersebut pada wilayah tertentu. Berdasarkan analisis overlay dengan kriteria karakter fisik yang mencakup lebar dan kedalaman sungai, akses yaitu jalan inspeksi yang berada di tepi sungai, bangunan yaitu kepadatan hunian yang ada di tepi sungai, zona banjir dan dengan mempertimbangkan batas administrasi maka di dapatkan 3 bagian sungai. Bagian sungai I terdiri dari Kelurahan Gilingan, Manahan, Mangkubumen dan Punggawan. Bagian Sungai II terdiri dari Kelurahan Kestalan, Ketelan, Setabelan, Keprabon, Kampung Baru, Kepatihan Kulon dan Kepatihan Wetan. Bagian Sungai III terdiri dari Kelurahan Sudiroprajan, Gandekan, Sewu, Kedunglumbu dan Sangkrah.

\section{Karaktristik Revitalisasi Kali Pepe Hilir}

Revitalisasi sungai yang dilakukan di Kali Pepe Hilir merupakan usaha atau upaya Dinas Pekerjaan Umum khususnya bidang drainase dan cipta karya dalam mengelola Kali Pepe Hilir untuk mengembalikan fungsi dan kondisi Kali Pepe Hilir sebagai saluran drainase primer dalam sistem drainase Kota Surakarta. Upaya tersebut dilakukan dengan mmuat 2 aspek yaitu fisik dansosial yang menjadi lingkup tugas dari DPU itu sendiri. Intervensi fisik merupakan kegiatan oleh DPU terkait dengan pembangunan dan perawatan fisik yang dilakukan di badan sungai dan bantaran sungai sedangkan intervensi sosial yaitu kegiatan oleh DPU terkait dengan pendekatan terhadap 
masyarakat yang tinggal di sekitar Kali Pepe Hilir yang dapat mempengaruhi kondisi sungai maupun bantaran sungai tersebut.

Tabel 1. Intensitas KegiatanRevitalisasi Kali Pepe Hilir

\begin{tabular}{|c|c|c|c|c|}
\hline $\begin{array}{c}\text { Bagian } \\
\text { Wilaya } \\
\text { h } \\
\text { Sungai }\end{array}$ & $\begin{array}{l}\text { Waktu } \\
\text { Pelaks } \\
\text { anaan }\end{array}$ & $\begin{array}{c}\text { Elemen } \\
\text { Revitalisa } \\
\text { si yang } \\
\text { Terkait }\end{array}$ & $\begin{array}{c}\text { Lokasi } \\
\text { Kegiata } \\
\text { n }\end{array}$ & $\begin{array}{c}\text { Keteranga } \\
n\end{array}$ \\
\hline \multirow{5}{*}{ I } & 2008 & Fisik & $\begin{array}{c}\text { Sebagia } \\
n\end{array}$ & \multirow{5}{*}{$\begin{array}{l}\text { Revitalisas } \\
\text { i Sungai } \\
\text { dengan } \\
\text { intensitas } \\
\text { sedang }\end{array}$} \\
\hline & 2010 & Sosial & $\begin{array}{c}\text { Seluruh } \\
\text { bagian }\end{array}$ & \\
\hline & \multirow{2}{*}{2012} & Fisik & $\begin{array}{c}\text { Sebagia } \\
\mathrm{n}\end{array}$ & \\
\hline & & Sosial & $\begin{array}{c}\text { Seluruh } \\
\text { bagian }\end{array}$ & \\
\hline & 2013 & Fisik & $\begin{array}{l}\text { Satu } \\
\text { titik }\end{array}$ & \\
\hline \multirow{5}{*}{ II } & \multirow{2}{*}{2010} & Fisik & $\begin{array}{l}\text { Satu } \\
\text { titik }\end{array}$ & \multirow{5}{*}{$\begin{array}{c}\text { Revitalisas } \\
\text { i Sungai } \\
\text { dengan } \\
\text { intensitas } \\
\text { sedang }\end{array}$} \\
\hline & & Sosial & $\begin{array}{c}\text { Seluruh } \\
\text { bagian }\end{array}$ & \\
\hline & 2012 & Sosial & $\begin{array}{c}\text { Seluruh } \\
\text { bagian }\end{array}$ & \\
\hline & \multirow{2}{*}{2013} & Fisik & $\begin{array}{c}\text { Seluruh } \\
\text { bagian }\end{array}$ & \\
\hline & & Sosial & $\begin{array}{c}\text { Seluruh } \\
\text { bagian }\end{array}$ & \\
\hline \multirow{3}{*}{ III } & 2010 & Sosial & $\begin{array}{l}\text { Seluruh } \\
\text { bagian }\end{array}$ & \multirow{3}{*}{$\begin{array}{c}\text { Revitalisa } \\
\text { si Sungai } \\
\text { dengan } \\
\text { intensitas } \\
\text { sedang }\end{array}$} \\
\hline & 2012 & Sosial & $\begin{array}{l}\text { Seluruh } \\
\text { bagian }\end{array}$ & \\
\hline & 2013 & Fisik & $\begin{array}{c}\text { Sebagi } \\
\text { an }\end{array}$ & \\
\hline
\end{tabular}

Sumber: Analisis, 2015

Kegiatan intervensi fisik sebagai implementasi dari program revitalisasi Kali Pepe Hilir lebih banyak dilakukan dibandingkan intervensi sosial. $\mathrm{Hal}$ tersebut dikarenakan kegiatan intervensi fisik lebih berdampak langsung terhadap kinerja Kali Pepe Hilir sebagai saluran primer dalam siStem drainase Kota Surakarta (DPU, 2015). Kegiatan intervensi sosial sudah dilakukan namun intensitasnya tidak sebesar intervensi fisik karena pendekatan terhadap masyarakat secara informal membutuhkan proses yang cukup lama untuk dapat mengubah pandangan dan kebiasaan masyarakat dalam menjaga keberlangsungan sungai. Revitalisasi Kali Pepe Hilir yang dilakukan oleh DPU Kota Surakarta selama tahun 2008-2013 dapat dikategorikan dalam revitalisasi sungai dengan intensitas sedang. $\mathrm{Hal}$ ini dikarenakan pada ketiga bagian sungai Kali Pepe Hilir tidak secara rutin dilakukan kegiatan revitalisasi baik kegiatan intervensi fisik maupun sosial. Selain itu, juga hanya terdapat dua elemen revitalisasi saja, yakni fisik dan sosial, yang menjadi dasar dari kegiatan revitalisasi sungai yang dilakukan oleh DPU tersebut.

\section{Perubahan Kinerja Sistem Drainase Kali Pepe Hilir}

Hasil dari analisis paired sample $t$ test, pada bagian sungai I terjadi perubahan pada seluruh indikator teknis kinerja sistem drainase, namun pada indikator kebiasaan masyarakat membuang sampah ke sungai pada aspek non teknis tidak mengalami perubahan. Dan berdasarkan analisis skoring, angka perubahan terbesar (dibandingkan dengan bagian sungai yang lain) terdapat pada indikator kondisi talud yaitu sebesar 11 poin. Karena tidak semua indikator kinerja drainase mengalami perubahan, maka pada bagian sungai I perubahan kinerja sistem drainase yang terjadi adalah kurang signifikan.

Pada bagian sungai II, seluruh indikator baik pada aspek teknis maupun non teknis terjadi perubahan karena dilakukannya revitalisasi sungai. Dan berdasarkan analisis skoring, angka perubahan terbesar terdapat pada indikator tingkat sedimentasi yaitu sebesar 38 poin, indikator kebiasaan masyarakat membuang sampah ke sungai sebesar 18 poin dan indikator rutinitas masyarakat membuang sampah ke sungai sebesar 6 poin. Karena semua indikator kinerja drainase mengalami perubahan, maka pada bagian sungai II perubahan kinerja sistem drainase yang terjadi adalah perubahan yang signifikan.

Sedangkan pada bagian sungai III perubahan yang terjadi sama dengan bagian sungai I. Yaitu terjadi perubahan pada seluruh indikator teknis kinerja sistem drainase, namun pada indikator kebiasaan masyarakat membuang sampah ke sungai pada aspek non teknis tidak mengalami perubahan. Dan berdasarkan analisis skoring, angka perubahan terbesar terdapat pada indikator penumpukan sampah yaitu sebesar 21 poin. Sama dengan bagian 
sungai I, dimana tidak semua indikator kinerja drainase mengalami perubahan, maka perubahan kinerja sistem drainase pada bagian sungai III dapat dikatakan sebagai perubahan yang kurang signifikan.

\section{Pengaruh Revitalisasi Sungai Terhadap Kinerja Sistem Drainase Kali Pepe Hilir}

Di bagian sungai I dimana revitalisasi sungai yang dilakukan adalah revitalisasi dengan intensitas sedang dan perubahan kinerja drainase yang terjadi kurang signifikan, dapat diidentifikasi bahwa revitalisasi sungai yang telah dilakukan di bagian sungai I berpengaruh kuat terhadap kinerja sistem drainase Kali Pepe Hilir bagian I dan berdampak perubahan pada sebagian wilayah sungai. Berpengaruh kuat karena keterangan dari revitalisasi maupun perubahan kinerja berada pada posisi sedang, yaitu tidak tinggi maupun tidak rendah. Berdampak perubahan pada sebagian wilayah sungai di sini maksudnya adalah revitalisasi akan memberi dampak perubahan kinerja sistem drainase pada sebagian wilayah tepi sungai pada bagian sungai I.

Revitalisasi sungai berpengaruh kuat dan berdampak pada sebagian wilayah di bagian sungai I dapat dilihat pada kesesuaian antara bentuk kegiatan revitalisasi yang dilakukan dengan angka perubahan kinerja sistem drainase terbesar (dibandingkan bagian sungai II dan bagian sungai III). Angka perubahan kinerja sistem drainase terbesar di bagian sungai I adalah angka perubahan pada indikator kondisi talud sebesar 11 poin. Dan kegiatan revitalisasi sungai yang diimplementasikan di bagian sungai I yang sesuai dengan perubahan angka kinerja terbesar adalah penambahan talud yang dilakukan di Kelurahan Gilingan dan Mangkubumen. Berdampak pada sebagian wilayah sungai bisa dilihat dari perubahan kondisi talud yang hanya terjadi di Kelurahan Gilingan dan Mangkubumen saja. Sehingga dapat disimpulkan bahwa pada bagian sungai I intervensi fisik program revitalisasi sungai mempengaruhi aspek teknis pada kinerja sistem drainase Kali Pepe Hilir.

Di bagian sungai II, dimana revitalisasi sungai yang dilakukan dengan intensitas sedang dan perubahan kinerja drainase yang signifikan, dapat diidentifikasi bahwa revitalisasi sungai yang telah dilakukan di bagian sungai II berpengaruh terhadap kinerja sistem drainase Kali Pepe Hilir bagian II dan berdampak pada seluruh bagian wilayah sungai. Berdampak pada selurah bagian wilayah sungai disini maksudnya adalah revitalisasi akan memberi dampak perubahan kinerja sistem drainase pada seluruh wilayah tepi sungai yang menjadi wilayah penelitian pada bagian sungai II.

Pada bagian sungai II, revitalisasi sungai berpengaruh dan berdampak pada seluruh wilayah di bagian sungai II dapat dilihat pada kesesuaian antara bentuk kegiatan revitalisasi yang dilakukan dengan angka perubahan kinerja sistem drainase terbesar (dibandingkan bagian sungai I dan bagian sungai III). Angka perubahan kinerja sistem drainase terbesar di bagian sungai II adalah angka perubahan pada indikator tingkat sedimentasi (sebesar 38 poin), kebiasaan masyarakat membuang sampah ke sungai (sebesar 18 poin), dan rutinitas masyarakat membersihkan sungai (sebesar 6 poin). Dan kegiatan revitalisasi sungai yang diimplementasikan di bagian sungai II yang sesuai dengan perubahan angka kinerja terbesar, diantaranya adalah sosialisasi larangan membuang sampah ke sungai pada tahun 2010 di sepanjang Kali Pepe Hilir di bagian sungai II, pengerukan yang dilakukan di Kelurahan Setabelan, Keprabon, Kepatihan Kulon, Kepatihan Wetan dan Kampungbaru pada tahun 2013 serta kegiatan sosialisasi terkait dengan pemeliharaan Kali Pepe Hilir sesuai dengan PP no 38 tahun 2011 di lima kelurahan yang sama Sehingga dapat disimpulkan bahwa pada bagian sungai II intervensi fisik program revitalisasi sungai mempengaruhi aspek teknis pada kinerja sistem drainase Kali Pepe Hilir, dan intervensi sosial mempengaruhi 
aspek non-teknis pada kinerja sistem drainase.

Di bagian sungai III dimana revitalisasi sungai yang dilakukan dengan intensitas sedang dan perubahan kinerja drainase yang kurang signifikan, dapat di identifikasi bahwa revitalisasi sungai yang telah dilakukan di bagian sungai III berpengaruh kuat terhadap kinerja sistem drainase Kali Pepe Hilir bagian I dan berdampak perubahan pada sebagian wilayah sungai. Berpengaruh kuat karena keterangan dari revitalisasi maupun perubahan kinerja berada pada posisi sedang, yaitu tidak tinggi maupun tidak rendah. Berdampak perubahan pada sebagian wilayah sungai disini maksudnya adalah revitalisasi akan memberi dampak perubahan kinerja sistem drainase pada sebagian wilayah tepi sungai pada bagian sungai III.

Pada bagian sungai III, revitalisasi sungai berpengaruh kuat dan berdampak pada sebagian wilayah di bagian sungai III dapat dilihat pada hubungan kesesuaian antara bentuk kegiatan revitalisasi yang dilakukan dengan angka perubahan kinerja sistem drainase terbesar (dibandingkan bagian sungai I dan bagian sungai II). Angka perubahan kinerja sistem drainase terbesar di bagian sungai III adalah angka perubahan pada indikator penumpukan sampah (sebesar 21 poin) dan genangan (sebesar 735.299). Dan kegiatan revitalisasi sungai yang diimplementasikan di bagian sungai III yang sesuai dengan perubahan angka kinerja terbesar adalah pengerukan yang dilakukan pada tahun 2013 di sepanjang Kali Pepe Hilir. Berdampak pada sebagian wilayah sungai bisa dilihat dari masih terjadinya genangan di Kelurahan Sangkrah, Sewu, Gandekan dan Sudiroprajan di tahun 2014. Sehingga dapat disimpulkan bahwa pada bagian sungai III intervensi fisik program revitalisasi sungai mempengaruhi aspek teknis pada kinerja sistem drainase Kali Pepe Hilir

Pengaruh revitalisasi sungai terhadap kinerja sistem drainase Kali Pepe Hilir juga dapat dilihat pada perubahan kinerja sistem drainase pada satu wilayah. Dengan menggunakan cara yang sama seperti saat melakukan analisis pengaruh revitalisasi sungai terhadap kinerja drainase pada tiap bagian sungai, penilaian ini juga dilakukan pada masing-masing indikator baik pada aspek teknis maupun non teknis kinerja sistem drainase pada seluruh bagian sungai yang digabung menjadi satu.

Tabel 2.Perubahan Indikator Kinerja Sistem Drainase pada wilayah Penelitian

\begin{tabular}{|c|c|c|}
\hline $\begin{array}{l}\text { Indikator } \\
\text { Kinerja } \\
\text { Drainase }\end{array}$ & Hasil Analisis & Keterangan \\
\hline $\begin{array}{l}\text { Kondisi } \\
\text { talud }\end{array}$ & $\begin{array}{l}\text { - tidak ada hubungan } \\
\text { - terjadi perubahan, } \\
\text { perubahan menurun }\end{array}$ & $\begin{array}{l}\text { Revitalisasi } \\
\text { sungai } \\
\text { mempengaruhi } \\
\text { perubahan } \\
\text { indikator } \\
\text { kondisi talud } \\
\end{array}$ \\
\hline $\begin{array}{l}\text { Tingkat } \\
\text { sedimenta } \\
\text { si }\end{array}$ & $\begin{array}{l}\text { - ada hubungan, } \\
\text { dengan angka } \\
\text { korelasi yang rendah } \\
\text { - terjadi perubahan, } \\
\text { perubahan menurun }\end{array}$ & $\begin{array}{l}\text { Revitalisasi } \\
\text { sungai } \\
\text { mempengaruhi } \\
\text { perubahan } \\
\text { indikator } \\
\text { tingkat } \\
\text { sedimentasi } \\
\end{array}$ \\
\hline $\begin{array}{l}\text { Penumpuka } \\
\text { n sampah }\end{array}$ & $\begin{array}{l}\text { - ada hubungan, } \\
\text { dengan angka } \\
\text { korelasi yang rendah } \\
\text { - terjadi perubahan, } \\
\text { perubahan menurun }\end{array}$ & $\begin{array}{l}\text { Revitalisasi } \\
\text { sungai } \\
\text { mempengaruhi } \\
\text { perubahan } \\
\text { indikator } \\
\text { penumpukan } \\
\text { sampah } \\
\end{array}$ \\
\hline Genangan & $\begin{array}{l}\text { terjadi perubahan, } \\
\text { perubahan menurun }\end{array}$ & $\begin{array}{l}\text { Revitalisasi } \\
\text { sungai } \\
\text { mempengaruhi } \\
\text { perubahan } \\
\text { indikator } \\
\text { genangan } \\
\end{array}$ \\
\hline $\begin{array}{l}\text { Kebiasaan } \\
\text { masyarak } \\
\text { at } \\
\text { membuan } \\
\text { g sampah } \\
\text { ke sungai }\end{array}$ & $\begin{array}{l}\text { - ada hubungan, } \\
\text { dengan angka } \\
\text { korelasi yang tinggi } \\
\text { - terjadi perubahan, } \\
\text { perubahan menurun }\end{array}$ & $\begin{array}{l}\text { Revitalisasi } \\
\text { sungai } \\
\text { mempengaruhi } \\
\text { perubahan } \\
\text { indikator } \\
\text { kebiasaan } \\
\text { masyarakat } \\
\text { membuang } \\
\text { sampah ke } \\
\text { sungai }\end{array}$ \\
\hline $\begin{array}{l}\text { Rutinitas } \\
\text { masyarak } \\
\text { at } \\
\text { members } \\
\text { ihkan } \\
\text { sungai }\end{array}$ & $\begin{array}{l}\text { - ada hubungan, } \\
\text { dengan angka } \\
\text { korelasi yang sangat } \\
\text { tinggi } \\
\text { - terjadi perubahan, } \\
\text { perubahan menurun }\end{array}$ & $\begin{array}{l}\text { Revitalisasi } \\
\text { sungai } \\
\text { mempengaruhi } \\
\text { perubahan } \\
\text { indikator } \\
\text { Rutinitas } \\
\text { masyarakat } \\
\text { membersihkan } \\
\text { sungai }\end{array}$ \\
\hline
\end{tabular}

Sumber: Analisis, 2015

Dari penilaian tersebut diketahui bahwa semua indikator kinerja sistem drainase mengalami perubahan karena adanya revitalisasi sungai. Perubahan tersebut merupakan perubahan kondisi yang lebih baik untuk seluruh indikator 
pada kinerja sistem drainase Kali Pepe Hilir dari sebelum dilakukannya revitalisasi dan sesudah dilakukannya revitalisasi. Sistem drainase perkotaan dikatakan baik karena terjadi perubahan meningkat pada indikator kondisi talud dan kebiasaan masyarakat membersihkan sungai, serta terjadi perubahan penurunan pada indikator tingkat sedimentasi, penumpukan sampah, genangan dan kebiasaan masyarakat membuang sampah ke sungai

\section{KESIMPULAN}

Penelitian ini dapat dinyatakan bahwa revitalisasi Kali Pepe Hilir yang dilakukan oleh DPU Kota Surakarta sesuai dengan pendapat Maryono (2007) bahwa revitalisasi sungai yaitu suatu usaha untuk mengembalikan fungsifungsi sungai yang salah satunya adalah fungsi sebagai saluran drainase. Revitalisasi sungai yang dilakukan oleh DPU Kota Surakarta merupakan upaya untuk mengembalikan fungsi Kali Pepe Hilir sebagai saluran drainase primer dan termasuk dalam bagian sistem drainase Kota Surakarta. Kembalinya fungsi sungai sebagai saluran drainase pada Kali Pepe Hilir ditandai dengan perubahan kinerja drainase Kali Pepe Hilir yang membaik dari sebelum dilakukan revitalisasi sungai dengan sesudah dilakukan revitalisasi sungai.

\section{REFERENSI}

Atmaka, FX. Nanang Agus Tri. 2004. Evaluasi Normalisasi Sungai Bengawan Solo Hulu dengan Konsep Eko-Hidraulik. Surakarta: Universitas Sebelas Maret

Maryono, Agus. 2007. Eko-Hidrolik Pengelolaan Sungai Ramah Lingkungan. Gajah Mada University Press. Yogyakarta

Suryanti, Irma, I N Norken, I G B Sila Dharma. 2013. Kinerja Sistem Jaringan Drainase Kota Semapura di Kabupaten Klunkung. Jurnal Spektran Vol 1 No 1 Januari 2013. Bali: Universitas Udayana

Kepmen PU No 266 Tahun 2010 tentang Pola Pengelolaan Sumber Daya
Air Wilayah Sungai Bengawan Solo

SK Menteri Pekerjaan Umum No 233

Tahun 1987 tentang Sistem Drainase 


\section{LAMPIRAN}

Tabel 1. Rincian Kegiatan Intervensi Fisik Program Revitalisasi Kali Pepe Hilir

\begin{tabular}{|c|c|c|}
\hline Tahun & Kegiatan & Pelaksana \\
\hline 2008 & $\begin{array}{l}\text { Penambahan dan perbaikan talud di Kelurahan } \\
\text { Gilingan dan Mangkubumen }\end{array}$ & DPU Bidang Drainase \\
\hline 2010 & $\begin{array}{l}\text { Perbaikan talud Kali Pepe (belakang mie gajah mas } \\
\text { pasar gede) }\end{array}$ & DPU Bidang Drainase \\
\hline \multirow[t]{2}{*}{2012} & $\begin{array}{l}\text { Pemeliharaan Berkala Saluran Dan operasional } \\
\text { Pengendalian Banjir di Kelurahan Kestalan Dan } \\
\text { Kelurahan Gilingan }\end{array}$ & DPU Bidang Drainase \\
\hline & $\begin{array}{l}\text { Pembersihan saluran Kali Pepe Jembatan Jl. Setia } \\
\text { Budi s/d Jembatann Jl. Bido Kel. Gilingan }\end{array}$ & DPU Bidang Drainase \\
\hline \multirow{7}{*}{2013} & $\begin{array}{l}\text { Pembersihan saluran Kali Pepe Hilir di Kelurahan } \\
\text { mangkubumen }\end{array}$ & DPU Bidang Drainase \\
\hline & $\begin{array}{l}\text { Pengerukan sedimen sepanjang Kali Pepe Hilir } \\
\text { (Kelurahan Gandekan, Sangkrah, Sudiroprajan, } \\
\text { Kampung Baru, Keprabon, Kepatihan Kulon, } \\
\text { Kepatihan Wetan dan Setabelan) }\end{array}$ & DPU Bidang Drainase \\
\hline & $\begin{array}{l}\text { Bersih bersih Kali Pepe dalam program "Indonesia } \\
\text { Bersih" }\end{array}$ & DPU Bidang Drainase \\
\hline & $\begin{array}{l}\text { Penataan sebagian kawasan bantaran sungai di } \\
\text { Kelurahan Sudiroprajan }\end{array}$ & $\begin{array}{l}\text { DPU Bidang Cipta Karya } \\
\text { DPU Bidang Drainase, }\end{array}$ \\
\hline & $\begin{array}{l}\text { Penataan lingkungan permukiman di bantaran Kali } \\
\text { Pepe Hillir Kelurahan Setabelan }\end{array}$ & DPU Bidang Cipta Karya \\
\hline & $\begin{array}{l}\text { Penataan lingkungan permukiman di bantaran Kali } \\
\text { Pepe Hillir Kelurahan Keprabon }\end{array}$ & DPU Bidang Cipta Karya \\
\hline & $\begin{array}{l}\text { Penataan bantaran Kali Pepe Hillir Kelurahan } \\
\text { Kampung Baru }\end{array}$ & DPU Bidang Cipta Karya \\
\hline
\end{tabular}

Sumber: DPU Kota Surakarta, 2015

Tabel 2. Rincian Kegiatan Intervensi Sosial Program Revitalisasi Kali Pepe Hilir

\begin{tabular}{|c|l|c|}
\hline Tahun & \multicolumn{1}{|c|}{ Kegiatan } & Pelaksana \\
\hline 2010 & $\begin{array}{l}\text { Sosialisai pemerintah kota terkait dengan penegasan Perda } \\
\text { No 3 Tahun 2010 tentang Pengelolaan Sampah. Yang salah } \\
\text { satu diantaranya disebutkan larangan membuang sampah di } \\
\text { sungai. }\end{array}$ & $\begin{array}{c}\text { DPU Drainase } \\
\text { DPU Cipta Karya }\end{array}$ \\
\hline 2012 & $\begin{array}{l}\text { Sayembaran penataan lingkungan permukiman kawasan } \\
\text { bantaran }\end{array}$ & DPU Cipta Karya \\
\hline 2013 & $\begin{array}{l}\text { Sosialisasi pemerintah kota kepada masyarakat terkait } \\
\text { dengan pemeliharaan Kali Pepe Hilir sesuai dengan PP no 38 } \\
\text { tahun 2011 }\end{array}$ & $\begin{array}{c}\text { DPU Drainase } \\
\text { DPU Cipta Karya }\end{array}$ \\
\hline
\end{tabular}

Sumber: DPU Kota Surakarta, 2015

Tabel 3. Perubahan Kinerja Sistem Drainase Kali Pepe Hilir

\begin{tabular}{|c|c|c|c|c|c|}
\hline & & & & & \\
\hline $\begin{array}{c}\text { Bagian } \\
\text { Wilayah } \\
\text { Sungai }\end{array}$ & Aspek & Indikator & $\begin{array}{c}\text { Angka } \\
\text { Perubaha } \\
\text { n }\end{array}$ & Perubahan & Keterangan \\
\hline \multirow{3}{*}{ 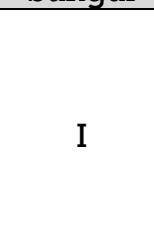 } & \multirow{3}{*}{ Teknis } & Tingkat Sedimentasi & 15 & $\begin{array}{l}\text { - Terjadi perubahan } \\
\text { - Perubahan menurun }\end{array}$ & \multirow{3}{*}{$\begin{array}{c}\text { Perubahan } \\
\text { Kinerja } \\
\text { Sistem } \\
\text { Drainase } \\
\text { yang Kurang } \\
\text { Signifikan }\end{array}$} \\
\hline & & Penumpukan Sampah & 14 & $\begin{array}{l}\text { - Terjadi perubahan } \\
\text { - Perubahan menurun }\end{array}$ & \\
\hline & & Kondisi Talud & 11 & $\begin{array}{l}\text { - Terjadi perubahan } \\
\text { - Perubahan }\end{array}$ & \\
\hline
\end{tabular}


Reza Eka dkk, Pengaruh Revitalisasi...

\begin{tabular}{|c|c|c|c|c|c|}
\hline $\begin{array}{l}\text { Bagian } \\
\text { Wilayah } \\
\text { Sungai } \\
\end{array}$ & Aspek & Indikator & $\begin{array}{c}\text { Angka } \\
\text { Perubaha } \\
n\end{array}$ & Perubahan & Keterangan \\
\hline & & & & meningkat & \\
\hline & & $\begin{array}{l}\text { Genangan (deskriptif } \\
\text { narasi) }\end{array}$ & $\begin{array}{c}\text { (Luas) } \\
243.311 \\
\end{array}$ & $\begin{array}{l}\text { - Terjadi perubahan } \\
\text { - Perubahan menurun }\end{array}$ & \\
\hline & Non & $\begin{array}{l}\text { Kebiasaan Membuang } \\
\text { Sampah ke sungai }\end{array}$ & 8 & $\begin{array}{l}\text { - Terjadi perubahan } \\
\text { - Perubahan menurun }\end{array}$ & \\
\hline & Teknis & $\begin{array}{l}\text { Rutinitas Masyarakat } \\
\text { Membersihkan Sungai }\end{array}$ & 3 & $\begin{array}{l}\text { Tidak terjadi } \\
\text { perubahan }\end{array}$ & \\
\hline \multirow{6}{*}{ II } & \multirow{4}{*}{ Teknis } & Tingkat Sedimentasi & 38 & $\begin{array}{l}\text { - Terjadi perubahan } \\
\text { - Perubahan menurun }\end{array}$ & \multirow{6}{*}{$\begin{array}{l}\text { Perubahan } \\
\text { Kinerja } \\
\text { Sistem } \\
\text { Drainase } \\
\text { yang } \\
\text { Signifikan }\end{array}$} \\
\hline & & Penumpukan Sampah & 18 & $\begin{array}{l}\text { - Terjadi perubahan } \\
\text { - Perubahan menurun }\end{array}$ & \\
\hline & & Kondisi Talud & 7 & $\begin{array}{l}\text { - Terjadi perubahan } \\
\text { - Perubahan } \\
\text { meningkat }\end{array}$ & \\
\hline & & $\begin{array}{l}\text { Genangan (deskriptif } \\
\text { narasi) }\end{array}$ & $\begin{array}{l}\text { (Luas) } \\
22.407 \\
\end{array}$ & $\begin{array}{l}\text { - Terjadi perubahan } \\
\text { - Perubahan menurun }\end{array}$ & \\
\hline & \multirow[b]{2}{*}{$\begin{array}{l}\text { Non } \\
\text { Teknis }\end{array}$} & $\begin{array}{l}\text { Kebiasaan Membuang } \\
\text { Sampah ke sungai }\end{array}$ & 18 & $\begin{array}{l}\text { - Terjadi perubahan } \\
\text { - Perubahan menurun }\end{array}$ & \\
\hline & & $\begin{array}{l}\text { Rutinitas Masyarakat } \\
\text { Membersihkan Sungai }\end{array}$ & 6 & $\begin{array}{l}\text { - Terjadi perubahan } \\
\text { - Perubahan } \\
\text { meningkat }\end{array}$ & \\
\hline \multirow{6}{*}{ III } & \multirow{4}{*}{ Teknis } & Tingkat Sedimentasi & 30 & $\begin{array}{l}\text { - Terjadi perubahan } \\
\text { - Perubahan menurun }\end{array}$ & \multirow{6}{*}{$\begin{array}{c}\text { Perubahan } \\
\text { Kinerja } \\
\text { Sistem } \\
\text { Drainase } \\
\text { yang Kurang } \\
\text { Signifikan }\end{array}$} \\
\hline & & Penumpukan Sampah & 21 & $\begin{array}{l}\text { - Terjadi perubahan } \\
\text { - Perubahan menurun }\end{array}$ & \\
\hline & & Kondisi Talud & 10 & $\begin{array}{l}\text { - Terjadi perubahan } \\
\text { - Perubahan } \\
\text { meningkat }\end{array}$ & \\
\hline & & $\begin{array}{l}\text { Genangan (deskriptif } \\
\text { narasi) }\end{array}$ & $\begin{array}{c}\text { (Luas) } \\
735.299 \\
\end{array}$ & $\begin{array}{l}\text { - Terjadi perubahan } \\
\text { - Perubahan menurun }\end{array}$ & \\
\hline & \multirow{2}{*}{$\begin{array}{c}\text { Non } \\
\text { Teknis }\end{array}$} & $\begin{array}{l}\text { Kebiasaan Membuang } \\
\text { Sampah ke sungai }\end{array}$ & 17 & $\begin{array}{l}\text { - Terjadi perubahan } \\
\text { - Perubahan menurun }\end{array}$ & \\
\hline & & $\begin{array}{l}\text { Rutinitas Masyarakat } \\
\text { Membersihkan Sungai }\end{array}$ & 0 & $\begin{array}{l}\text { Tidak terjadi } \\
\text { perubahan }\end{array}$ & \\
\hline
\end{tabular}

Sumber: analisis, 2015 


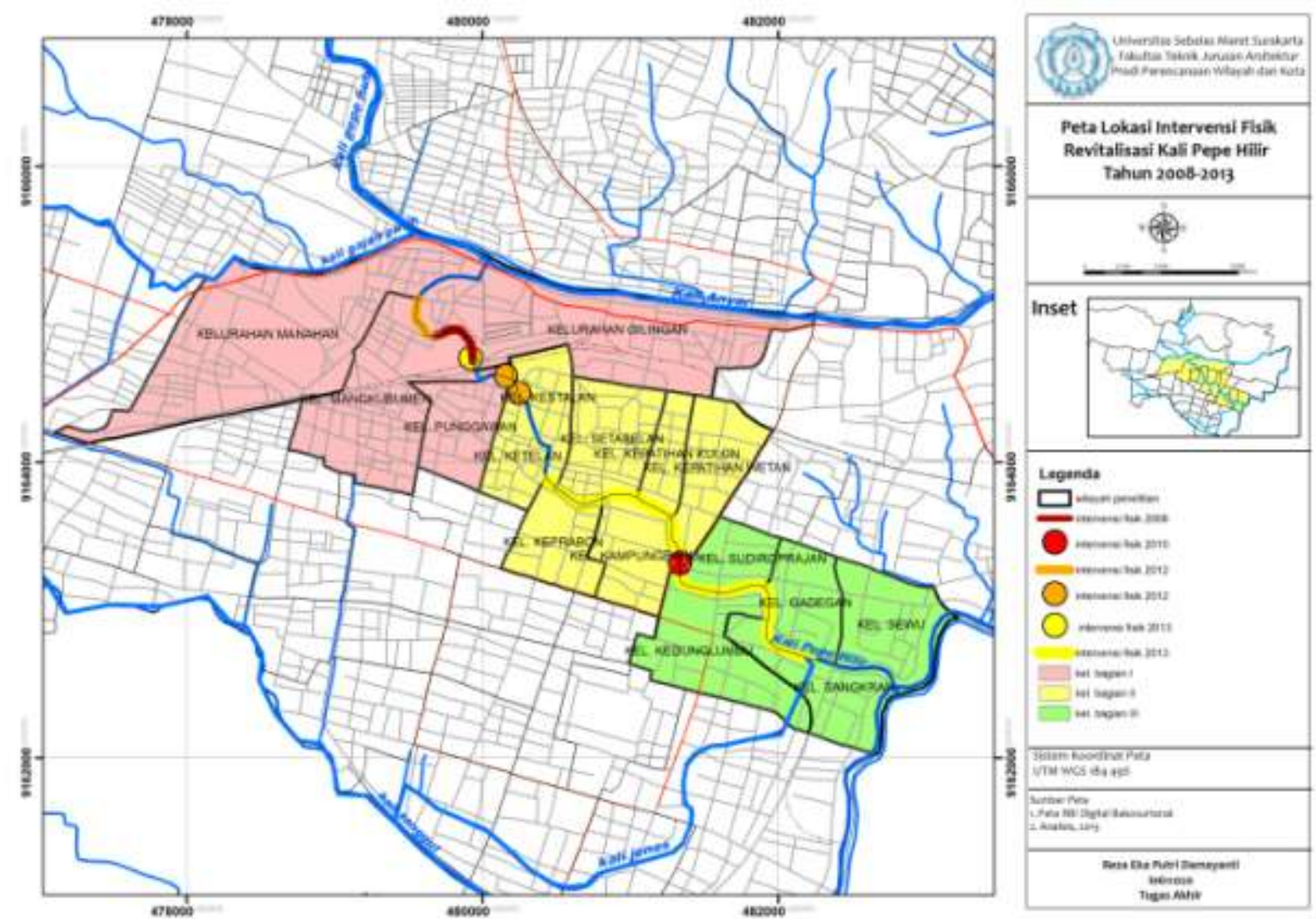

Gambar 1. Lokasi Kegiatan Intervensi Fisik Program Revitalisasi Kali Pepe Hilir Tahun 2008-2013 